\title{
Vantagens da Análise Custo/Volume/Lucro no Contexto de Pequena Fábrica de Blocos de Concreto
}

\author{
Rodney Wernke \\ Doutorado em Engenharia de Produção pela Universidade Federal de Santa Catarina - \\ UFSC \\ Sem vínculo Institucional \\ Rua Antônio Philippi, 312. Centro. São Ludgero/SC. CEP 88.730-000, Brasil \\ E-mail: rodneywernke1@hotmail.com
}

\section{RESUMO}

A pesquisa objetivou identificar as informações gerenciais decorrentes da aplicação da Análise Custo/Volume/Lucro no âmbito de uma pequena empresa de blocos de concreto. Para essa finalidade foi utilizada metodologia qualitativa, descritiva e no formato de estudo de caso. Entre os resultados está a obtenção das seguintes informações: (i) mensuração da lucratividade de produtos e grupos pela margem de contribuição fabril unitária e total (identificando aqueles que mais contribuem para o resultado operacional); (ii) conhecimento do ponto de equilíbrio do mix de vendas para identificar o patamar de faturamento para resultado nulo e/ou simular a quantidade a comercializar para atingir o valor de lucro necessário para remunerar o custo do capital aplicado e (iii) elaboração de demonstrativo do resultado de fácil compreensão pelos administradores da empresa e com a evidenciação da participação percentual dos fatores em relação ao faturamento. Portanto, a pesquisa contribuiu do ponto de vista prático, pois evidenciou como aplicar os conceitos da Análise CVL no contexto de uma pequena empresa industrial, especialmente por destacar a aderência dessa ferramenta gerencial nessa realidade fabril. Com isso, o gestor passou a dispor de informações gerenciais que anteriormente não dispunha nos controles internos utilizados na empresa quanto à lucratividade de produtos e grupos, ao nível do ponto de equilíbrio e acerca do resultado mensal.

Palavras-chave: Análise Custo/Volume/Lucro. Pequena fábrica. Estudo de caso.

\section{Advantages of Cost/Volume/Profit Analysis in the Context of a Small Factory of Concrete Blocks}

\section{ABSTRACT}

The research aims to identify the managerial information resulting from the application of Cost/Volume/Profit Analysis in the scope of a small concrete block company. For this purpose a qualitative, descriptive methodology and case study research was carried out. Among the results it was obtained the following information: (i) measurement of the profitability of products and groups by the unitary and total factory contribution margin 
(identifying those that contribute most to the operating result); (ii) knowledge of the balance point of the sales mix to identify the turnover level for a null result and/or simulate the quantity to be sold to reach the profit value necessary to remunerate the cost of capital applied and (iii) preparation of a text with the results that can be read and easily understand by the company's administrators, including the disclosure of the percentage participation of factors in relation to revenue. Therefore, the present research seems to contributed from a practical point of view, as it showed how to apply the concepts of CVP Analysis in the context of a small industrial company, especially by highlighting the adherence of this management tool in this industrial reality. The managers now have the managerial information that was not previously available in the internal controls used in the company regarding the profitability of products and groups, at the level of the break-even point and about the monthly result.

Keywords: Cost/Volume/Profit Analysis. Small factory. Case study.

\section{Ventajas del Análisis Coste/Volumen/Beneficio em el Contexto de una Pequeña Fábrica de Bloques de Hormigón}

\section{RESUMEN}

La investigación tuvo como objetivo identificar la información gerencial resultante de la aplicación del Análisis Costo/Volumen/Beneficio en el ámbito de una pequeña empresa de bloques de concreto. Para ello se utilizó metodología cualitativa, descriptiva y formato de estudio de caso. Entre los resultados se encuentra la obtención de la siguiente información: (i) medición de la rentabilidad de productos y grupos por el margen de contribución unitario y total de la fábrica (identificando aquellos que más aportan al resultado operativo); (ii) conocimiento del punto de equilibrio del mix de ventas para identificar el nivel de rotación para un resultado nulo y/o simular la cantidad a vender para alcanzar el valor de utilidad necesario para remunerar el costo de capital aplicado y (iii) preparación de un Declaración el resultado de fácil comprensión por parte de los administradores de la empresa y con la divulgación del porcentaje de participación de los factores en relación a los ingresos. Por tanto, la investigación aportó desde un punto de vista práctico, ya que mostró cómo aplicar los conceptos de Análisis CVL en el contexto de una pequeña empresa industrial, destacando especialmente la adherencia de esta herramienta de gestión en esta realidad industrial. Con esto, el gerente ahora cuenta con información gerencial que antes no estaba disponible en los controles internos utilizados en la empresa sobre la rentabilidad de productos y grupos, a nivel del punto de equilibrio y sobre el resultado del mes.

Palabras clave: Análisis de Costo/Volumen/Beneficio. Pequeña fábrica. Estudio de caso. 


\section{INTRODUÇÃO}

A literatura da área financeira menciona que a Análise Custo/Volume/Lucro (CVL) e seus componentes proporcionam informações relevantes para os administradores (Sulaiman, Ahmad, \& Alwi, 2004; Souza, Schnorr, \& Ferreira, 2011; Rasoto et al., 2012; D’Amato, Galvão, Villaça, Jorge, \& Tavares, 2012; Fonseca, 2012; Lima, Ferro, Bortoluzzi, Southier, \& Batistus, 2018; Wernke, 2019). Contudo, uma maior utilização da Análise CVL no âmbito de pequenas indústrias pode ser prejudicada pela complexidade de cálculo de alguns dos seus integrantes, especialmente em fábricas com grande mix de produtos à venda (Scheren, Wernke, Junges, \& Santos, 2019), o que dificulta a apuração da lucratividade dos itens faturados.

Além disso, quando se deparam com esse tipo de problema, os gestores de pequenas fábricas tendem a empregar metodologias simplificadas de custeamento (como dividir o custo total do mês pela quantidade produzida no período), o que pode acarretar valores inconsistentes de custo fabril unitário que distorcem a avaliação do resultado dos produtos (Lembeck \& Wernke, 2019).

Mas se o gestor conhecer adequadamente as vantagens derivadas da aplicação da Análise CVL na gestão industrial terá melhores condições de aproveitar as informações proporcionadas para subsidiar suas análises acerca de aumentar/reduzir o mix de produtos ofertados ou priorizar determinados segmentos de mercado (produtos, grupos etc.), entre outras possibilidades.

Nesta pesquisa, a partir desse pressuposto, pretende-se abordar a seguinte pergunta de estudo: quais as informações gerenciais que a Análise CVL proporciona no contexto de pequenas empresas fabris? Para responder tal questão foi fixado o objetivo de identificar as informações gerenciais decorrentes da aplicação da Análise CVL no âmbito de uma pequena indústria de blocos de concreto.

Pesquisas com essa finalidade se justificam pela relevância econômica das empresas industriais no Brasil, que em 2019 foram responsáveis por 33\% da arrecadação de tributos federais do país ( $R \$ 351,8$ bilhões) e empregaram formalmente 
9.723,6 mil pessoas, sendo que $3.412,8$ mil desses postos formais de trabalho estavam nas micro e pequenas empresas fabris (CNI, 2020). Portanto, aprimoramentos da gestão das pequenas fábricas podem ajudá-las a otimizar o desempenho financeiro e fortalecê-las perante a concorrência.

Outra justificativa relaciona-se com a necessidade de mais pesquisas acadêmicas sobre a adoção efetiva, por parte das empresas e dos artefatos de contabilidade gerencial discutidos na literatura (Baldvinsdottir, Mitchell, \& Norreklit, 2010; Lukka, 2010). Ou seja, como as empresas podem estar situadas em estágios gerenciais distintos, Oyadomari et al. (2013) aduzem que o posicionamento dos "práticos" pode ser objeto de estudos sobre a contabilidade gerencial, pois as pesquisas podem abordar também a realidade de uma empresa e não se ater apenas ao "estado da arte" sobre determinado assunto.

\section{FUNDAMENTAÇÃO TEÓRICA}

A Análise CVL costuma ser apresentada na literatura de finanças como uma ferramenta de apoio decisorial que envolve a interdependência de determinados fatores (preços de venda, custos e despesas fixos ou variáveis, quantidades produzidas ou vendidas etc.) e as respectivas influências no resultado do período, o que proporciona um conjunto de informações úteis para visualizar o desempenho da empresa e de segmentos de mercado (Colpo, Medeiros, Amorim, \& Weise, 2015). Assim sendo, a Análise CVL é um modelo matemático que evidencia os efeitos no resultado do período (ou no resultado projetado) de mudanças no volume faturado, nos preços de venda praticados, nos custos (fixos ou variáveis) e nas despesas operacionais da empresa (Wernke, 2019).

Porém, a Análise CVL está apoiada em suposições simplificadoras da realidade empresarial, como a premissa de que os volumes de produção e venda seriam os mesmos, o que desconsidera os níveis de estoques para produzir e comercializar os produtos no período (Leone \& Leone, 2008). Além disso, a margem de contribuição não 
abrange o conceito de "valor do dinheiro no tempo", pois desconsidera os efeitos dos prazos de pagamento de fornecedores, de recebimento de clientes e de estocagem dos insumos e produtos, o que pode influenciar fortemente nos resultados apurados (Scheren, Wernke, Junges, \& Santos, 2019).

Martins (2018) assevera que os integrantes da Análise CVL de maior destaque são o ponto de equilíbrio, a margem de contribuição e a margem de segurança. No caso da margem de contribuição, o referido autor menciona que o valor monetário dessa resulta da dedução dos custos e despesas variáveis do preço de venda do produto.

Quanto ao emprego desse conceito na avaliação da lucratividade de segmentos de mercado, Guerreiro (2011) aduz que não é a margem de contribuição unitária em valor monetário $(R \$)$ e nem a margem de contribuição unitária em percentual (\%) que reflete da melhor forma a lucratividade dos produtos. Exemplifica tal raciocínio argumentando que o produto " $\mathrm{A}$ " pode ter a maior margem de contribuição unitária percentual e o produto "B" a maior margem de contribuição unitária em valor monetário. No entanto, se o produto "C" gera a maior margem de contribuição total em valor monetário $(R \$)$, esse é o item que mais auxilia no pagamento dos custos fixos e formação do lucro da empresa. Portanto, o produto "C" deve ser considerado o mais rentável.

No que tange ao ponto de equilíbrio, esse pode ser caracterizado como a quantidade física a ser vendida para que o faturamento total cubra os custos variáveis e fixos da empresa, de modo que o montante comercializado proporcione margem de contribuição total cujo valor iguale a soma dos custos e despesas fixos, gerando resultado nulo (Bornia, 2010).

Para determinar o ponto de equilíbrio em unidades basta dividir o valor total dos custos/despesas fixos $(R \$)$ do período pelo valor da margem de contribuição total $(R \$)$, conforme Souza e Diehl (2009). Porém, essa forma de cálculo do ponto de equilíbrio é cabível apenas para empresas que produzem/vendem somente um produto ou quando se adota uma margem "média" de contribuição para o conjunto de itens comercializados 
no período, o que tende a distorcer o resultado oriundo (Wernke, 2019).

Um modo de minimizar tal limitação consiste em utilizar a fórmula do ponto de equilíbrio mix, que considera a totalidade dos produtos concomitantemente (Santos, 2005; Assaf Neto \& Lima, 2009). Nesse sentido, Assaf Neto e Lima (2009) demonstra essa equação com o exemplo de um posto de combustíveis que vendeu 8.500 litros e teve custos fixos de $\mathrm{R} \$ 4.000$ no período. Desse faturamento mensal, $29,41 \%$ (2.500 litros) do volume vendido foram de gasolina, 23,53\% (2.000 litros) foram de diesel e $47,06 \%$ (4.000 litros) foram de álcool, o que gerou $R \$ 5.700$ de margem de contribuição total. Destarte, com a fórmula do ponto de equilíbrio mix (em unidades) apura-se que o nível de equilíbrio da empresa seria atingido com a venda de 5.964,91 litros [R $\$ 4.000 /$ ( $R \$ 5.700 / 8.500$ litros)], que seriam suficientes para equiparar as receitas totais com os custos fixos do período. Posteriormente, para individualizar esse total de litros para os três tipos de combustíveis vendidos é necessário dividi-lo em proporção aos percentuais respectivos da quantidade vendida no período. Com isso, o ponto de equilíbrio mix (em unidades) segregado por tipo de produto seria de 2.807,02 litros de álcool $(47,06 \%$ do total), de $1.403,51$ litros de diesel (23,53\% do total) e de $1.754,39$ litros de gasolina $(29,41 \%$ do total).

Ao comparar o nível de vendas com o patamar do ponto de equilíbrio, apura-se a margem de segurança. Ou seja, esse conceito da Análise CVL é medido pela diferença entre a quantidade vendida e o volume calculado como ponto de equilíbrio (Silva \& Lins, 2017). Então, se as vendas do mês alcançarem 500 unidades e o ponto de equilíbrio for de 400 unidades, o volume faturado pode cair até 100 unidades que a empresa ainda não entrará na faixa de prejuízo.

\subsection{Pesquisas anteriores assemelhadas}

No que concerne a estudos publicados em periódicos acerca da Análise CVL, uma pesquisa a respeito no Portal de Periódicos Capes, efetuada no mês de novembro de 2020, enumerou os artigos resumidos no Quadro 1. 


\begin{tabular}{|c|c|}
\hline Autores & Principais Aspectos \\
\hline $\begin{array}{c}\text { Moraes e } \\
\text { Wernke (2006) }\end{array}$ & $\begin{array}{l}\text { Aplicação da Análise CVL numa empresa de pesca com objetivo de obter informações sobre a } \\
\text { margem de contribuição unitária e total dos produtos vendidos, identificar o ponto de equilíbrio } \\
\text { (em } \mathrm{R} \$ \text { e em quilos) e a respectiva margem de segurança, além de apurar o resultado mensal. }\end{array}$ \\
\hline $\begin{array}{l}\text { Schultz, Borgert e } \\
\text { Hofer (2006) }\end{array}$ & $\begin{array}{l}\text { Em empresa agropecuária, utilizaram a Análise CVL para auxiliar no planejamento do fluxo } \\
\text { produtivo, com apoio do ponto de equilíbrio e considerando o ciclo de produção. }\end{array}$ \\
\hline $\begin{array}{c}\text { Leone e } \\
\text { Leone (2008) }\end{array}$ & $\begin{array}{l}\text { Evidenciaram que o modelo matemático da Análise CVL se assenta em premissas } \\
\text { simplificadoras da realidade de curto prazo, mostrando matematicamente as consequências } \\
\text { dessas simplificações. }\end{array}$ \\
\hline $\begin{array}{c}\text { Sichigea e } \\
\text { Ciurezu (2009) }\end{array}$ & $\begin{array}{l}\text { A Análise CVL serviu para avaliar o efeito da tentativa de eliminação dos concorrentes e de } \\
\text { prática de monopólio político pelas maiores empresas e elencaram ações de política econômica } \\
\text { que facultam diminuir práticas como dumping e concorrência desleal. }\end{array}$ \\
\hline $\begin{array}{l}\text { Carmen e } \\
\text { Sorin }(2010)\end{array}$ & $\begin{array}{l}\text { Priorizaram a evidenciação da aplicação da Análise CVL nas decisões do contexto de } \\
\text { empresas que atuam com hospitalidade. }\end{array}$ \\
\hline $\begin{array}{l}\text { Dianawati } \\
(2010)\end{array}$ & $\begin{array}{l}\text { Como o modelo matemático da Análise CVL não abrange a incerteza, este estudo apresentou } \\
\text { metodologia para inserir este aspecto durante o processo de tomada de decisão no âmbito do } \\
\text { setor de hotelaria. }\end{array}$ \\
\hline $\begin{array}{c}\text { Trifan e } \\
\text { Anton (2011) }\end{array}$ & $\begin{array}{l}\text { A Análise CVL deveria considerar as eventuais flutuações no nível de atividade, o que requer a } \\
\text { classificação das despesas em "fixas" e "variáveis" nas simulações a respeito do resultado, bem } \\
\text { como nas análises decisoriais. }\end{array}$ \\
\hline $\begin{array}{l}\text { Souza, Schnorr } \\
\text { e Ferreira (2011) }\end{array}$ & $\begin{array}{l}\text { A pesquisa destacou a utilização da Análise CVL em três indústrias de grande porte gaúchas e } \\
\text { mostrou que o uso prático dos conceitos relacionados não é intenso nesse rol de empresas. }\end{array}$ \\
\hline $\begin{array}{l}\text { Deviarti e } \\
\text { Ayu (2011) }\end{array}$ & $\begin{array}{l}\text { Com base no contexto de uma indústria de material elétrico, dessumiram que a aplicação do } \\
\text { ponto de equilíbrio para múltiplos produtos permite melhorias na projeção dos lucros da } \\
\text { empresa. }\end{array}$ \\
\hline $\begin{array}{l}\text { Jonny } \\
(2012)\end{array}$ & $\begin{array}{l}\text { Utilização da Análise CVL numa companhia de pedágios para avaliar se o preço contratado } \\
\text { proporcionaria a remuneração de capital desejada pelos investidores do empreendimento. }\end{array}$ \\
\hline $\begin{array}{l}\text { Leoncine, Bornia } \\
\text { e Abbas (2012) }\end{array}$ & $\begin{array}{l}\text { Visando o aprimoramento da gestão dos resultados operacionais de entidade hospitalar, } \\
\text { apresentaram modelo de apuração dos custos por procedimento médico por meio de conceitos } \\
\text { inerentes à Análise CVL. }\end{array}$ \\
\hline $\begin{array}{l}\text { Wibowo } \\
(2012)\end{array}$ & $\begin{array}{l}\text { Relato da aplicação da Análise CVL no contexto de empresas de hotelaria no período que } \\
\text { abrange os anos de } 2009 \text { a } 2011 \text {. }\end{array}$ \\
\hline $\begin{array}{c}\text { Johnson e } \\
\text { Sargent (2013) }\end{array}$ & $\begin{array}{l}\text { Discorreram sobre como a influência de fatores associados à linguagem, ao uso de fórmulas e } \\
\text { a instruções específicas afeta o entendimento de universitários na solução de problemas } \\
\text { didáticos acerca da Análise CVL. }\end{array}$ \\
\hline $\begin{array}{l}\text { Banker, Basu, } \\
\text { Byzalov e Chen } \\
(2013)\end{array}$ & $\begin{array}{l}\text { Ao destacar a existência de assimetrias de custos no contexto da Análise CVL, esta pesquisa } \\
\text { desenvolveu um modelo matemático assimétrico capaz de demonstrar que as variações } \\
\text { assimétricas podem alterar os resultados oriundos. }\end{array}$ \\
\hline $\begin{array}{c}\text { Gani } \\
(2013)\end{array}$ & $\begin{array}{l}\text { Descreve a aplicação da Análise CVL numa indústria têxtil visando projetar o mix de produtos } \\
\text { que proporcionaria o melhor resultado econômico. }\end{array}$ \\
\hline $\begin{array}{l}\text { Santos, Marion } \\
\text { e Kettle (2014) }\end{array}$ & $\begin{array}{l}\text { A Análise CVL foi utilizada no processo produtivo de leite de fazenda experimental de uma } \\
\text { universidade para mensurar o resultado da produção leiteira e conhecer o ponto de equilíbrio. }\end{array}$ \\
\hline $\begin{array}{c}\text { Colpo, Medeiros, } \\
\text { Amorim e Weise } \\
(2015)\end{array}$ & $\begin{array}{l}\text { Utilização da Análise CVL em pequena fábrica de calçados evidenciou que esta pode contribuir } \\
\text { na definição de estratégias para gerenciar a produção e a venda de pequenas indústrias. }\end{array}$ \\
\hline $\begin{array}{l}\text { Etges, Calegari, } \\
\text { Rhoden e } \\
\text { Cortimiglia (2016) }\end{array}$ & $\begin{array}{l}\text { A Análise CVL foi empregada para avaliar a viabilidade da construção de centro de distribuição } \\
\text { para uma indústria de produtos farmacêuticos. }\end{array}$ \\
\hline $\begin{array}{c}\text { Chirilov e } \\
\text { Mihaila (2016) }\end{array}$ & $\begin{array}{l}\text { O objetivo foi utilizar a Análise CVL como forma aprimorar o resultado e facilitar a tomada de } \\
\text { decisões econômicas baseadas no ponto de equilíbrio e na margem de contribuição. }\end{array}$ \\
\hline
\end{tabular}




\begin{tabular}{|c|c|}
\hline $\begin{array}{l}\text { Bergo, Lucas, } \\
\text { Sobreiro e } \\
\text { Nagano }(2016)\end{array}$ & $\begin{array}{l}\text { Os conceitos da Análise CVL foram empregados para simular a realocação de recursos } \\
\text { produtivos para maximizar o resultado da empresa utilizando um algoritmo baseado na receita } \\
\text { financeira individualizada por produto. }\end{array}$ \\
\hline $\begin{array}{l}\text { Ekergil } \\
(2017)\end{array}$ & $\begin{array}{l}\text { Para segmentar a clientela de determinada empresa foi adotada a Análise CVL com o intuito de } \\
\text { identificar a lucratividade de cada cliente. }\end{array}$ \\
\hline $\begin{array}{l}\text { Ilie e } \\
\text { Ileana-Sorina } \\
(2017)\end{array}$ & $\begin{array}{l}\text { Evidenciaram que Análise CVL mostra as mudanças no resultado da empresa em decorrência } \\
\text { de alteração na quantidade vendida, no preço de venda unitário e nos custos de produção de } \\
\text { uma companhia de petróleo e gás natural. }\end{array}$ \\
\hline $\begin{array}{l}\text { Wernke, } \\
\text { Faccenda e } \\
\text { Junges (2017) }\end{array}$ & $\begin{array}{l}\text { Demonstraram que a Análise CVL é aplicável à realidade de escola de idiomas e destacaram } \\
\text { um rol de informações úteis para os gestores desse tipo de prestadora de serviços. }\end{array}$ \\
\hline $\begin{array}{c}\text { Guarini e } \\
\text { Battisti (2017) }\end{array}$ & $\begin{array}{l}\text { Adaptaram as análises do ponto de equilíbrio e da margem de contribuição às decisões } \\
\text { relacionadas com o planejamento de intervenções imobiliárias e nas iniciativas de } \\
\text { desenvolvimento e reciclagem de imóveis em Parceiras Público-Privadas. }\end{array}$ \\
\hline $\begin{array}{l}\text { Chu, Libby, } \\
\text { Mathiey e Zhang } \\
(2017)\end{array}$ & $\begin{array}{l}\text { A Análise CVL foi utilizada num contexto de tensão em decisões de curto e longo prazo, de } \\
\text { modo a complementar a análise do fluxo de caixa descontado, com o fito de mensurar os } \\
\text { efeitos de incentivos gerenciais ligados a iniciativas de melhoria da lucratividade. }\end{array}$ \\
\hline $\begin{array}{l}\text { Carmen-Elena } \\
(2018)\end{array}$ & $\begin{array}{l}\text { Discorreu sobre a relação de dependência entre os três indicadores da Análise CVL visando } \\
\text { comprovar a necessidade de rastrear e melhorar continuamente esses fatores para otimizar as } \\
\text { decisões dos gestores. }\end{array}$ \\
\hline $\begin{array}{l}\text { Schultz } \\
(2018)\end{array}$ & $\begin{array}{l}\text { Caso de ensino elaborado com a intenção de demonstrar a aplicação da Análise CVL numa } \\
\text { padaria que fabrica produtos personalizados para facilitar decisões relacionadas ao mix de } \\
\text { vendas e aos preços praticados. }\end{array}$ \\
\hline $\begin{array}{l}\text { Lima, Ferro, } \\
\text { Bortoluzzi, } \\
\text { Southier e } \\
\text { Batistus (2018) }\end{array}$ & $\begin{array}{l}\text { Numa empresa monoprodutora defenderam a incorporação da Análise de Sensibilidade e da } \\
\text { Análise de Cenários nas simulações de ponto de equilíbrio, como forma de melhorar a } \\
\text { confiabilidade das informações oriundas. }\end{array}$ \\
\hline $\begin{array}{l}\text { Andriani } \\
(2018)\end{array}$ & $\begin{array}{l}\text { Estudou a aplicabilidade da Análise CVL na } \\
\text { ponto de equilíbrio e a lucratividade das turn }\end{array}$ \\
\hline $\begin{array}{l}\text { Aslan e } \\
\text { Yilmaz (2018) }\end{array}$ & $\begin{array}{l}\text { Proposta de inclusão da lógica Fuzzy no âmbito da Análise CVL para facilitar as análises em } \\
\text { condições de incerteza do negócio e possibilitar a projeção de lucros com margem de erro de } \\
\text { aproximadamente } 7 \% \text {. }\end{array}$ \\
\hline $\begin{array}{l}\text { Santos, Cruz, } \\
\text { Santos e Leone } \\
(2018)\end{array}$ & $\begin{array}{l}\text { Evidenciaram como uma distribuidora de medicamentos poderia melhorar a Margem de } \\
\text { Contribuição (MC) e a Margem Bruta }(\mathrm{MB}) \text { dos produtos ofertados. }\end{array}$ \\
\hline $\begin{array}{l}\text { Pitoyo } \\
(2018)\end{array}$ & $\begin{array}{l}\text { O Custeio Baseado em Atividade (ABC) foi utilizado junto com a Análise CVL para identificar a } \\
\text { lucratividade das operações de uma fábrica que recicla papelão, metal e plástico. }\end{array}$ \\
\hline $\begin{array}{l}\text { Winarko e } \\
\text { Astuti (2018) }\end{array}$ & $\begin{array}{l}\text { Relataram a aplicação dos conceitos de ponto de equilíbrio, ma } \\
\text { de segurança numa linha de produção de indústria de pias para }\end{array}$ \\
\hline $\begin{array}{l}\text { Scheren, Wernke, } \\
\text { Junges e Santos } \\
\text { (2019) }\end{array}$ & $\begin{array}{l}\text { Demonstraram as etapas as serem seguidas para adoção da Análise CVL no contexto de } \\
\text { pequena fábrica de alimentos, que produzia grande variedade de produtos. }\end{array}$ \\
\hline $\begin{array}{l}\text { Mihalciuc e } \\
\text { Grosu (2019) }\end{array}$ & $\begin{array}{l}\text { Propuseram um sistema de gestão estratégica do desempenho empresarial fundamentado nos } \\
\text { integrantes da Análise CVL. }\end{array}$ \\
\hline $\begin{array}{l}\text { Corrêa, Kliemann } \\
\text { Neto, Roos, Souza } \\
\text { e Amorin (2020) }\end{array}$ & $\begin{array}{l}\text { Apresentaram proposta de um método de balanceamento da Análise CVL em função da } \\
\text { capacidade de vendas no contexto de um empreendimento agropecuário. }\end{array}$ \\
\hline $\begin{array}{l}\text { Huels e } \\
\text { Weber (2020) }\end{array}$ & $\begin{array}{l}\text { Preocuparam-se em elaborar uma atividade para ensino da Análise CVL que foi pensada para } \\
\text { estimular os alunos a se envolverem com decisões gerenciais tomadas em empresa do reality } \\
\text { show Shark Tank. }\end{array}$ \\
\hline
\end{tabular}

\section{Quadro 1. Publicações sobre Análise CVL}

Fonte: elaborado pelo autor. 
Como visto, há poucas publicações em periódicos sobre a Análise CVL que discorrem acerca da aplicação dessa ferramenta gerencial no âmbito de pequenas empresas industriais, o que pode gerar dúvidas acerca da sua aderência a esse tipo e porte de empreendimento. Por isso, neste estudo se pretende evidenciar os benefícios decorrentes dos conceitos de margem de contribuição, ponto de equilíbrio e margem de segurança no contexto desse tipo de fábrica e porte empresarial.

\section{CARACTERÍSTICAS METODOLÓGICAS}

Quanto à caracterização da metodologia utilizada, essa pode ser classificada como "descritiva", "qualitativa" e "estudo de caso". A classificação quanto aos objetivos como descritiva é adequada porque Gil (1999) registra que essa categoria se refere aos estudos que visam descrever as características de uma determinada população/fenômeno ou o estabelecimento de relações entre as variáveis existentes no contexto abrangido.

Em relação à forma de abordagem do problema pode ser considerada como qualitativa porque Richardson (1999) aduz que este tipo de estudo aborda a complexidade de um problema, analisa a interação das variáveis, além de compreender e classificar os processos vividos por grupos sociais. Ainda, acerca do procedimento empregado é conveniente considerar como estudo de caso porque se concentra num único objeto de estudo (uma pequena fábrica de blocos de concreto), como mencionado por Yin (2005).

No que tange ao contexto empresarial abrangido, o objeto da pesquisa foi uma pequena indústria de blocos de concreto sediada em um município do sul de Santa Catarina, cuja identificação foi omitida por solicitação do proprietário. À época do estudo a entidade contava com seis empregados na área operacional e os dois sócios na parte administrativa, enquanto a contabilidade da firma estava a cargo de empresa terceirizada. Nesse sentido, é pertinente caracterizá-la como pequena empresa, de 
acordo com o parâmetro adotado pelo Sebrae (2019), onde indústrias com até 99 funcionários pertencem a essa categoria de porte empresarial.

Quanto ao método de trabalho utilizado, esse pode ser sintetizado nas seguintes fases:

1) Levantamento de dados: os dados numéricos obtidos (como quantidades físicas e valores monetários de vendas, custos fabris, tributos incidentes, despesas etc.) referem-se ao mês de novembro de 2020 e abrangem todos os produtos comercializados no período (como lajotas, meios-fios, blocos, pisos podo táteis etc.), conforme levantamento realizado nos controles internos da empresa;

2) Obtenção de informações adicionais: foram obtidas com os dois gestores e com o responsável pela contabilidade (terceirizada) por meio de entrevistas informais (não estruturadas) que objetivaram principalmente conhecer os controles internos adotados e o modo de mensurar a lucratividade dos produtos que vinha sendo utilizado;

3) Cálculo dos componentes da Análise CVL: a partir dos dados obtidos, em planilhas eletrônicas, foram aplicadas as fórmulas relacionadas com a margem de contribuição fabril, ponto de equilíbrio e margem de segurança conforme o mix dos produtos abrangidos, além da elaboração da demonstração do resultado do período.

\section{APRESENTAÇÃO DOS DADOS E DISCUSSÃO DOS RESULTADOS DA PESQUISA}

As próximas seções discorrem a respeito dos dados levantados, dos cálculos inerentes à aplicação da Análise CVL e sobre as informações gerenciais oriundas, além da discussão sobre os resultados obtidos.

\subsection{Levantamento dos dados utilizados}

No primeiro passo para aplicar os conceitos da Análise CVL na pequena 
indústria pesquisada, coletaram-se os dados necessários para calcular a margem de contribuição fabril dos produtos vendidos, como resumido na Tabela 1.

Tabela 1

Base de dados

\begin{tabular}{|c|c|c|c|c|c|c|}
\hline Produtos & Grupos & $\begin{array}{r}\text { Vendas } \\
\text { Total R\$ }\end{array}$ & $\begin{array}{r}\text { Custo de Matéria- } \\
\text { prima Total R\$ }\end{array}$ & $\begin{array}{l}\text { Tributos } \\
\text { Total } \mathbf{R} \$\end{array}$ & $\begin{array}{r}\text { Custo Fabril } \\
\text { Total } \mathbf{R} \$ \\
\end{array}$ & $\begin{array}{r}\text { Quantidade } \\
\text { Vendida }\end{array}$ \\
\hline $21 \times 6-C Z$ & $\mathrm{BCP}$ & $168.930,68$ & $83.089,37$ & $31.646,37$ & $18.683,97$ & 5.371 \\
\hline BC.4MP-14x19×39 & $\mathrm{BC}$ & $82.080,89$ & $20.251,00$ & $15.374,22$ & $6.193,42$ & 30.500 \\
\hline BCP. $10,5 \times 21 \times 8-C Z$ & $\mathrm{BCP}$ & 50.0 & $17.783,84$ & $9.388,99$ & $5.889,94$ & 1.518 \\
\hline BC.6MP-19x19×39 & $\mathrm{BC}$ & $46.769,27$ & $10.229,04$ & $8.760,58$ & $3.086,56$ & 11.400 \\
\hline MF. $30 \times 12 \times 10 \times 80$ & MF & $26.875,61$ & $5.728,88$ & $5.036,34$ & $2.209,86$ & 1.798 \\
\hline Outros. & - & $95.893,36$ & $27.566,69$ & $18.026,96$ & $16.946,88$ & 16.197 \\
\hline Total & - & $470.644,92$ & $164.648,80$ & $88.233,46$ & $53.010,62$ & 66.784 \\
\hline
\end{tabular}

Nota. Fonte: elaborada pelo autor.

Convém destacar que, em virtude da restrição de espaço no texto, são evidenciados de forma detalhada apenas os cinco produtos de maior faturamento, optando-se por representar os demais na linha "Outros..." nas tabelas deste artigo. Além disso, por exigência da empresa foram omitidos maiores detalhes acerca da identificação dos produtos (optando-se pelos códigos utilizados internamente) e dos grupos respectivos (conjunto de produtos semelhantes, cuja classificação facilita a análise de desempenho do mix comercializado).

No período pesquisado foram faturadas 66.784 unidades de 21 produtos, o que proporcionou receita bruta de $\mathrm{R} \$ 470.644,92$ e acarretou impostos incidentes sobre as vendas de $R \$ 88.233,46$. Ainda, a partir das quantidades vendidas dos produtos foram calculados os custos do consumo total de matérias-primas com base na ficha técnica de cada produto (o que totalizou $\mathrm{R} \$ 164.648,80$ no mês) e o custo fabril total do período ( $R \$ 53.010,62$ ), cujo valor unitário constava de planilha fundamentada no método das Unidades de Esforço de Produção (UEP) mantida pela empresa há quase dois anos. A disponibilidade desses dados por produto possibilitou calcular a margem de contribuição fabril, como descrito na próxima seção. 


\subsection{Margem de contribuição fabril dos produtos}

A etapa dois desta pesquisa priorizou a apuração da margem de contribuição (MC) fabril, que foi calculada pelos três ângulos citados na Tabela 2.

Tabela 2

Margem de contribuição por produto

\begin{tabular}{|c|c|c|c|}
\hline Produtos & $\begin{array}{r}\text { MC Fabril } \\
\text { Total R\$ }\end{array}$ & $\begin{array}{r}\text { MC Fabril } \\
\text { Unit. R\$ }\end{array}$ & $\begin{array}{r}\text { MC Fabril } \\
\text { Unit. \% }\end{array}$ \\
\hline BCP.10,5x21×6-CZ & $35.510,96$ & 6,61 & $21,02 \%$ \\
\hline BC.4MP-14x19×39 & $40.262,26$ & 1,32 & $49,05 \%$ \\
\hline BCP. $10,5 \times 21 \times 8-C Z$ & $17.032,35$ & 11,22 & $34,00 \%$ \\
\hline BC.6MP-19x19×39 & $24.693,10$ & 2,17 & $52,80 \%$ \\
\hline MF. $30 \times 12 \times 10 \times 80$ & $13.900,53$ & 7,73 & $51,72 \%$ \\
\hline Outros... & $33.352,84$ & 2,06 & $34,78 \%$ \\
\hline Total & $164.752,04$ & - & \\
\hline
\end{tabular}

Nota. Fonte: elaborada pelo autor.

A margem de contribuição fabril total (em $\mathrm{R} \$$ ) foi calculada descontando-se do (I) valor total vendido no mês, os valores relativos ao (ii) consumo de matérias-primas, aos (iii) tributos incidentes sobre as vendas e aos (iv) custos de fabricação relacionados a cada produto no período abrangido. Nesse caso, o conceito de margem de contribuição "fabril" se refere à concepção de Anthony e Govindarajan (2002), pois esses aduzem que do valor da margem de contribuição tradicional (preço de venda menos custos e despesas variáveis) deve ser descontado o valor do custo de fabricação do produto. Portanto, diferentemente do conceito tradicional de margem de contribuição, neste estudo se está considerando o custo de fabricação (geralmente "fixo") como um dos componentes do cálculo da margem de contribuição fabril.

Assim, no caso do "BCP.10,5x21x6-CZ", da venda mensal de $\mathrm{R} \$ 168.930,68$ foram descontados os custos das matérias-primas consumidas ( $R \$ 83.089,37$ ), os tributos sobre o faturamento $(R \$ 31.646,37)$ e o custo de fabricação $(R \$ 18.683,97)$ para chegar à margem de contribuição fabril total de $R \$ 35.510,96$.

Em seguida, para determinar a margem de contribuição fabril unitária em valor monetário (terceira coluna da Tabela 2), dividiu-se a margem de contribuição fabril total 


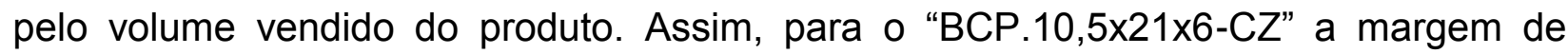
contribuição unitária foi de $R \$ 6,61$ ( $R \$ 35.510,96$ / 5.371 unidades). Posteriormente, calculou-se a margem de contribuição fabril unitária em percentual com a divisão da margem de contribuição fabril total $(\mathrm{R} \$ 35.510,96)$ pela venda total dessa mercadoria ( $R$ \$ 168.930,68), mostrando que o "BCP.10,5x21x6-CZ" proporcionou margem de lucro equivalente a $21,02 \%$ do preço de venda respectivo.

Foi constatado, então, a existência de produtos com margens fabris que

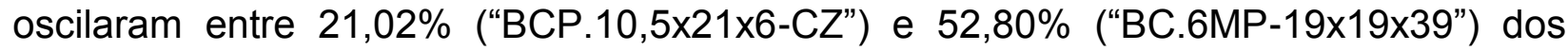
preços de venda respectivos. Entretanto, se considerados todos os 21 itens vendidos no mês, determinados produtos (omitidos na Tabela 2) apresentaram lucratividades mais baixas (até o patamar de 17\%).

Outra forma de analisar comparativamente a performance dos produtos consiste em avaliar as participações percentuais desses no faturamento total e na margem de contribuição fabril total, como exposto na Tabela 3.

Tabela 3

Participação nas vendas e na margem de contribuição total

\begin{tabular}{|c|c|c|c|c|c|}
\hline Produtos & $\begin{array}{r}\text { Vendas } \\
\text { Total R\$ }\end{array}$ & $\begin{array}{r}\% \text { das } \\
\text { Vendas }\end{array}$ & $\begin{array}{r}\text { MC Fabril } \\
\text { Total R\$ }\end{array}$ & $\begin{array}{l}\% \text { da } \\
\text { MCF }\end{array}$ & $\begin{array}{l}\text { Diferença entre o \% das } \\
\text { Vendas e o \% da MCF }\end{array}$ \\
\hline BCP.10,5x21x6-CZ & $168.930,68$ & $35,89 \%$ & $35.510,96$ & $21,55 \%$ & $14,34 \%$ \\
\hline BC.4MP-14x19×39 & $82.080,89$ & $17,44 \%$ & $40.262,26$ & $24,44 \%$ & $-7,00 \%$ \\
\hline BCP.10,5x21x8-CZ & $50.095,11$ & $10,64 \%$ & $17.032,35$ & $10,34 \%$ & $0,31 \%$ \\
\hline BC.6MP-19x19×39 & $46.769,27$ & $9,94 \%$ & $24.693,10$ & $14,99 \%$ & $-5,05 \%$ \\
\hline MF. $30 \times 12 \times 10 \times 80$ & $26.875,61$ & $5,71 \%$ & $13.900,53$ & $8,44 \%$ & $-2,73 \%$ \\
\hline Outros... & $95.893,36$ & $20,37 \%$ & $33.352,84$ & $20,24 \%$ & $0,13 \%$ \\
\hline Total & $470.644,92$ & $100,00 \%$ & $164.752,04$ & $100,00 \%$ & $0,00 \%$ \\
\hline
\end{tabular}

Nota. Fonte: elaborada pelo autor.

Nota-se que esse tipo de comparação é interessante porque um produto pode ser o mais vendido e não ser o melhor do ponto de vista da lucratividade (Wernke, 2019), como fica evidente ao serem confrontadas as participações dos produtos no faturamento mensal da empresa e na margem de contribuição fabril conseguida ao final 
do período.

No caso do produto "BCP.10,5x21x6-CZ", as vendas atingiram $\mathrm{R} \$ 168.930,68$ (o que representou $35,89 \%$ do total vendido no período), mas a margem de contribuição fabril foi de $\mathrm{R} \$ 35.510,96$ e equivale a $21,55 \%$ do montante do resultado fabril do mês.

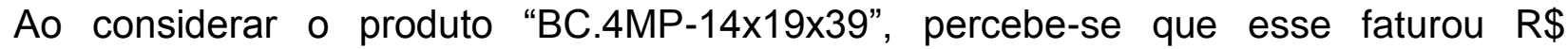
$82.080,89$ (17,44\% das vendas totais), mas propiciou margem de contribuição fabril total de $\mathrm{R} \$ 40.262,26$ (equivalente a $24,44 \%$ do valor total conseguido no mês). Ou seja, apesar de vender menos da metade do que foi comercializado do produto mais


fabril total no período abrangido.

$\mathrm{Na}$ última coluna da Tabela 3 consta a diferença entre as participações percentuais no faturamento do mês e na margem de contribuição fabril total de cada produto. Nesse sentido, dos cinco produtos priorizados, em três deles ("BC.4MP-

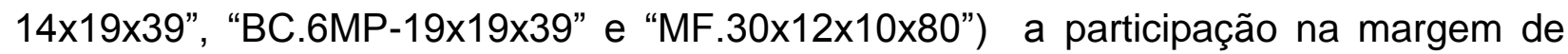
contribuição fabril total foi maior que a respectiva participação no valor das vendas do

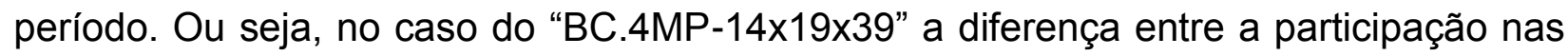
vendas totais $(17,44 \%)$ e a respectiva participação na margem de contribuição fabril total $(24,44 \%)$ foi de $-7,00 \%$, indicando que o produto tem menor participação percentual no faturamento do mês do que no resultado operacional.

\subsubsection{Margem de contribuição fabril dos grupos de produtos}

Entre as informações importantes que podem ser obtidas dos conceitos inerentes à Análise CVL está a avaliação do desempenho de grupos de produtos (entre outros segmentos de mercado), como evidenciado na Tabela 4 para os três tipos vendidos no mês pesquisado. 
Tabela 4

Desempenho por grupos de produtos

\begin{tabular}{lrrrr}
\hline \% das Vendas do Grupo & BCP & BC & MF & TOTAL \\
\hline (+)Vendas & $100,00 \%$ & $100,00 \%$ & $100,00 \%$ & $100,00 \%$ \\
(--)Consumo de Matérias-primas & $43,10 \%$ & $23,14 \%$ & $21,32 \%$ & $34,98 \%$ \\
(--)Tributos sobre vendas & $18,76 \%$ & $18,73 \%$ & $18,74 \%$ & $18,75 \%$ \\
(-)Custo Fabril & $10,86 \%$ & $12,47 \%$ & $8,22 \%$ & $11,26 \%$ \\
(=)MC Fabril & $27,28 \%$ & $45,66 \%$ & $51,72 \%$ & $35,01 \%$ \\
\hline \% do Total por Fator do Resultado & $\mathbf{B C P}$ & $\mathbf{B C}$ & $\mathbf{M F}$ & TOTAL \\
\hline (+)Vendas & $59,87 \%$ & $34,42 \%$ & $5,71 \%$ & $100,00 \%$ \\
(--)Consumo de Matérias-primas & $73,75 \%$ & $22,77 \%$ & $3,48 \%$ & $100,00 \%$ \\
(--)Tributos sobre vendas & $59,90 \%$ & $34,39 \%$ & $5,71 \%$ & $100,00 \%$ \\
(--)Custo Fabril & $57,74 \%$ & $38,09 \%$ & $4,17 \%$ & $100,00 \%$ \\
(=)MC Fabril & $46,66 \%$ & $44,90 \%$ & $8,44 \%$ & $100,00 \%$ \\
\hline
\end{tabular}

Nota. Fonte: elaborada pelo autor.

Na primeira parte da Tabela 4 constam as margens de contribuição fabris médias da empresa e das três linhas comercializadas. Enquanto a média da empresa ficou em $35,01 \%$ das vendas, o grupo dos "Blocos de concreto para pavimentos (BCP)" proporcionou $27,28 \%$ de margem média e o grupo dos "Blocos de concreto (BC)" trouxe 45,66\% no mesmo parâmetro. Contudo, o grupo de produtos "Meio-fio (MF)" foi o de melhor desempenho, com $51,72 \%$ de margem média.

Além disso, na parte inferior da Tabela 4 ("\% do Total por Fator do Resultado") pode ser visualizada a participação de cada grupo nas vendas do mês e na margem de contribuição fabril total. O grupo "MF" foi o que teve o menor percentual do faturamento (5,71\% do total) e a menor participação na margem de contribuição fabril total do período (8,44\%). No caso do grupo "BCP", este foi responsável por $59,87 \%$ do faturamento e participou com $46,66 \%$ da contribuição total do mês. Por sua vez, o grupo "BC" respondeu por $34,42 \%$ das vendas, mas trouxe $44,90 \%$ da margem de contribuição fabril total auferida. Assim sendo, apesar de faturar pouco mais da metade das vendas conseguidas pelo grupo "BCP", a linha de produtos "BC" propiciou quase o mesmo valor total de lucro fabril. 


\subsection{Ponto de equilíbrio das operações}

O cálculo da margem de contribuição fabril total de cada produto permite determinar o ponto de equilíbrio da situação atual da empresa e/ou simular cenários para, por exemplo, dimensionar as vendas necessárias para atingir determinado valor de lucro, como demonstrado na Tabela 5.

Tabela 5

Ponto de equilíbrio (Etapa Inicial)

\begin{tabular}{lrr}
\hline Itens & Situação Atual & Cenário Desejado \\
\hline 1) Total de Despesas Fixas R\$ & $47.234,98$ & $47.234,98$ \\
2) Lucro Desejado/Outros Pagamentos R\$ & - & $120.000,00$ \\
3=1+2) Total a cobrir no Ponto de Equilíbrio R\$ & $47.234,98$ & $167.234,98$ \\
4) Margem de Contribuição Total R\$ & $164.752,04$ & $164.752,04$ \\
5) Quantidade Vendida (unidades) & 66.784 & 66.784 \\
6=[3/(4/5)] Ponto de Equilíbrio (unidades) & $19.147,20$ & $67.790,49$ \\
$7=5-6)$ Margem de Segurança (unidades) & $47.636,80$ & $-1.006,49$ \\
\hline
\end{tabular}

Nota. Fonte: elaborada pelo autor.

A determinação do ponto de equilíbrio em unidades da situação vigente (linha "6" da segunda coluna da Tabela 5) requereu o levantamento dos seguintes dados: (I) valor total das despesas fixas mensais (linha "1"), que no caso dessa fábrica no mês pesquisado chegou a $R \$ 47.234,98$ e abrange os gastos não fabris (como folha de pagamentos da parte administrativa, licenças de softwares, contador, internet, telefonia etc.); (ii) valor da margem de contribuição fabril total $(\mathrm{R} \$ 164.752,04)$ e (iii) a quantidade física total vendida no mês (66.784 unidades). Então, utilizando a equação mencionada em seção anterior, apurou-se que o ponto de equilíbrio mix seria de 19.147,20 unidades no contexto do período abrangido. Assim, considerando que o faturamento em unidades foi maior que a quantidade necessária para atingir o ponto de equilíbrio, cabe dizer que a fábrica operou com margem de segurança de 47.636,80 unidades no mês do estudo (linha "7" da segunda coluna da Tabela 5). Convém salientar que as frações de unidades de blocos de concreto apuradas nas duas últimas linhas da Tabela 5 , mesmo que inexistentes em termos da realidade desses produtos, foram mantidas em 
tal ilustração para facilitar o entendimento das duas próximas tabelas deste texto.

Por outro prisma, se os proprietários da fábrica quiserem estimar o volume a ser vendido para lucrar determinado valor mensalmente, podem adaptar a equação do ponto de equilíbrio para projetar tal cenário. Para essa finalidade, como consta da última coluna da Tabela 5 , deve ser somado o valor das despesas fixas mensais $(R \$$ 47.234,98) com o lucro almejado ( $\mathrm{R} \$ 120.000,00$ como exemplo hipotético) para definir o valor a ser atingido no ponto de equilíbrio ( $R \$ 167.234,98)$ com a margem de contribuição respectiva gerada. Então, assumindo-se a manutenção dos demais valores, a fórmula do ponto de equilíbrio mostra que será necessário vender 67.790,49 unidades, o que é um volume superior àquele vendido no mês da pesquisa e indica margem de segurança negativa de 1.006,49 unidades. Portanto, para atingir o lucro desejado seria necessário vender 1.006,49 unidades além do que foi vendido no mês citado, mantida a mesma proporção dos produtos no mix faturado.

Contudo, é relevante ressalvar que o nível previsto para o ponto de equilíbrio informa a quantidade de todos os produtos de modo concomitante. Como esses têm valores de margem de contribuição fabril díspares, é pertinente individualizar o ponto de equilíbrio para cada mercadoria vendida, como demonstrado na Tabela 6.

Tabela 6

Ponto de Equilíbrio por Produto (Etapa Intermediária)

\begin{tabular}{|c|c|c|c|c|}
\hline Produtos & $\begin{array}{r}\text { Partic. na Quant. } \\
\text { Vendida (\%) }\end{array}$ & $\begin{array}{r}\text { Ponto de Equilíbrio } \\
\text { em Unidades }\end{array}$ & $\begin{array}{r}\text { Preço Venda } \\
\text { Unitário R\$ }\end{array}$ & $\begin{array}{r}\text { Ponto de Equilíbrio } \\
\text { em Valor R\$ }\end{array}$ \\
\hline BCP. $10,5 \times 21 \times 6-C Z$ & $8,04 \%$ & $1.539,88$ & 31,45 & $48.433,01$ \\
\hline BC.4MP-14x19×39 & $45,67 \%$ & $8.744,46$ & 2,69 & $23.532,88$ \\
\hline BCP. $10,5 \times 21 \times 8-C Z$ & $2,27 \%$ & 435,22 & 33,00 & $14.362,44$ \\
\hline BC.6MP-19x19×39 & $17,07 \%$ & $3.268,42$ & 4,10 & $13.408,91$ \\
\hline MF. $30 \times 12 \times 10 \times 80$ & $2,69 \%$ & 515,49 & 14,95 & $7.705,33$ \\
\hline Outros... & $24,25 \%$ & $4.643,74$ & - & $27.492,96$ \\
\hline Total & $100,00 \%$ & $19.147,20$ & - & $134.935,53$ \\
\hline
\end{tabular}

Nota. Fonte: elaborada pelo autor.

Para apurar os valores (em unidades e em $\mathrm{R} \$$ ) cabíveis a cada produto do mix comercializado no mês foi necessário calcular o percentual de participação dos 
produtos na quantidade total faturada, como consta da segunda coluna da Tabela 6 . No passo seguinte esses percentuais foram multiplicados pelo volume calculado como ponto de equilíbrio da empresa (19.147,20 unidades) para determinar a quantidade deste total que corresponde a cada um dos produtos. No caso do produto

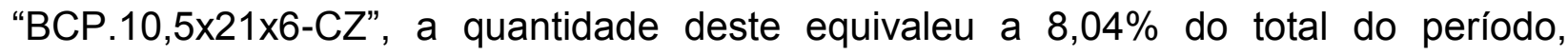
mostrando que lhe cabem 1.539,8 unidades das $19.147,20$ relativas ao ponto de equilíbrio da empresa.

O passo final consistiu em multiplicar o preço de venda unitário do produto (quarta coluna da Tabela 6) pelo ponto de equilíbrio em unidades respectivo. Assim,

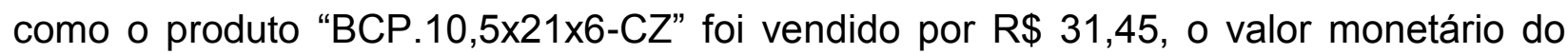
seu ponto de equilíbrio seria $R \$ 48.433,01$. Ao efetuar cálculo idêntico com todos os produtos faturados no período, chegou-se ao valor total de $R \$ 134.935,53$, que equivale ao montante que a fábrica precisaria faturar para equilibrar custos, despesas e receitas no mês abrangido pelo estudo.

Uma terceira etapa relacionada ao cálculo do ponto de equilíbrio é "opcional" e consiste em comprovar matematicamente que o volume estimado é suficiente para cobrir as despesas do período, como evidenciado na Tabela 7.

Tabela 7

Comprovação do Ponto de Equilíbrio Por Produto (Etapa Final)

\begin{tabular}{|c|c|c|c|}
\hline Produtos & $\begin{array}{r}\text { Ponto de Equilíbrio } \\
\text { em Unidades }\end{array}$ & $\begin{array}{r}\text { Margem de Contribuição } \\
\text { Fabril Unitária R\$ }\end{array}$ & $\begin{array}{r}\text { Margem de Contribuição } \\
\text { Fabril Total R\$ }\end{array}$ \\
\hline BCP. $10,5 \times 21 \times 6-C Z$ & $1.539,88$ & 6,61 & $10.181,12$ \\
\hline 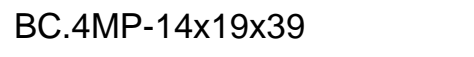 & $8.744,46$ & 1,32 & $11.543,33$ \\
\hline BCP. $10,5 \times 21 \times 8-C Z$ & 435,22 & 11,22 & $4.883,23$ \\
\hline BC.6MP-19x19×39 & $3.268,42$ & 2,17 & $7.079,60$ \\
\hline 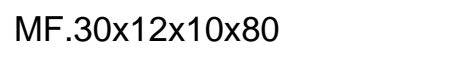 & 515,49 & 7,73 & $3.985,33$ \\
\hline Outros... & $4.643,74$ & - & $9.562,37$ \\
\hline Total no ponto de equilíbrio & $19.147,20$ & - & $47.234,98$ \\
\hline \multicolumn{3}{|c|}{ (--) Despesas fixas do período $R \$$} & $47.234,98$ \\
\hline \multicolumn{3}{|c|}{ (=) Resultado no ponto de equilíbrio $\mathrm{R} \$$} & 0,00 \\
\hline
\end{tabular}

Nota. Fonte: elaborada pelo autor. 
A quantidade projetada de ponto de equilíbrio deve proporcionar margem de contribuição fabril total que iguale os custos/despesas fixos do mês. Então, ao multiplicar o ponto de equilíbrio em unidades de cada produto pela margem de contribuição fabril unitária (em $\mathrm{R} \$$ ), obtém-se o valor que cada produto contribuirá para

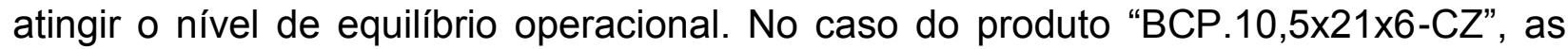
$1.539,88$ unidades calculadas como ponto de equilíbrio foram multiplicadas por $R \$ 6,61$ (margem de contribuição fabril unitária) para chegar no valor de $\mathrm{R} \$ 10.181,12$ de margem de contribuição fabril total. Então, aplicando-se o mesmo cálculo para os demais produtos e somando-se os valores da última coluna da Tabela 7 chega-se ao valor total de $\mathrm{R} \$ 47.234,98$, que é igual ao valor das despesas fixas e indica a exatidão do nível de ponto de equilíbrio calculado.

\subsection{Resultado do período}

Outra informação útil para o gestor de uma pequena fábrica que é obtida a partir da Análise CVL consiste em determinar o resultado do período com base nos dados anteriormente citados.

No caso da pequena indústria em lume, o resultado mensal está representado na Tabela 8.

Tabela 8

Resultado do período

\begin{tabular}{lrr}
\hline Itens & Valor R\$ & \% das Vendas \\
\hline (+) Vendas do mês & $470.644,92$ & $100,00 \%$ \\
(--) Consumo de matérias-primas & $164.648,80$ & $34,98 \%$ \\
(--) Tributos sobre vendas & $88.233,46$ & $18,75 \%$ \\
(-) Custo fabril & $53.010,62$ & $11,26 \%$ \\
(=) Margem de contribuição fabril & $164.752,04$ & $35,01 \%$ \\
(-) Despesas fixas do mês & $47.234,98$ & $10,04 \%$ \\
(=) Resultado do período & $117.517,06$ & $24,97 \%$ \\
\hline
\end{tabular}

Nota. Fonte: elaborada pelo autor.

Assim sendo, das receitas com vendas do mês ( $R \$ 470.644,92)$ foram descontados os valores do (i) consumo de matérias-primas pelos produtos vendidos 
( $\mathrm{R} \$ 164.648,80)$, dos (ii) tributos incidentes sobre o faturamento ( $\mathrm{R} \$ 88.233,46)$ e do (iii) custo fabril ( $R \$ 53.010,62)$ para encontrar a margem de contribuição total, que chegou a $\mathrm{R} \$ 164.752,04$. Ao descontar as despesas fixas do mês ( $R \$ 47.234,98)$, apurou-se o resultado do período $(\mathrm{R} \$ 117.517,06)$. Destarte, com base na terceira coluna da Tabela 8, pode-se concluir que a margem de contribuição média foi de $35,01 \%$ das vendas, que as despesas fixas equivaleram a $10,04 \%$ do faturamento e que a margem líquida operacional foi de $24,97 \%$.

\subsection{Análise dos resultados e cotejamento com pesquisas assemelhadas}

Como o foco deste estudo consistia em identificar as informações gerenciais decorrentes da aplicação da Análise CVL no âmbito de uma pequena indústria, a partir do exposto nas seções anteriores foi possível segregar tais benefícios em três categorias.

A primeira classe diz respeito à margem de contribuição fabril, que pode ser subdividida em quatro aspectos:

a) Margem de contribuição fabril unitária (em $R$ \$ e percentual): evidenciada na Tabela 2, possibilita conhecer o valor monetário $(R \$)$ que cada produto traz por unidade vendida, bem como o quanto esse valor equivale, em termos percentuais (\%), do preço de venda unitário respectivo. Essas informações permitem que o gestor avalie a lucratividade unitária de cada produto e facilitam as decisões ligadas à necessidade de majorar preços, descontos a conceder, viabilidade de promoções etc.;

b) Margem de contribuição fabril total dos produtos: resumida na Tabela 3, essa informação é aplicável à identificação de quais são os itens que proporcionaram as maiores arrecadações de recursos para o de caixa da pequena fábrica no período. Ao estabelecer um ranking a respeito, o gestor pode selecionar os itens prioritários ou os que merecem ser descartados do mix ofertado;

c) Comparação entre os percentuais de participação no faturamento do mês e na margem de contribuição fabril total: destacadas na Tabela 3, essas informações 
evidenciam que os produtos participam de forma diferente na geração de caixa a partir das vendas e no faturamento mensal. Portanto, as vendas de determinado item podem ser as maiores do conjunto de produtos faturados no período, mas esse não ser o mais lucrativo. Assim, conforme Wernke (2019), o gestor da empresa deve priorizar o parâmetro "margem de contribuição fabril total", em vez das "vendas totais" dos produtos no mês, quando do ranqueamento dos integrantes do mix vendido;

d) Margem de contribuição fabril total dos grupos de produtos: na Tabela 4 consta 0 desempenho dos grupos de produtos, indicando quais são os mais lucrativos, além de compará-los quanto à participação percentual nas vendas e na margem de contribuição fabril total.

As informações geradas sobre a lucratividade obtida pelos produtos e grupos de produtos corroboram as menções na literatura acerca da conveniência de utilizar a margem de contribuição para avaliar a lucratividade de segmentos de mercado (Warren, Reeve, \& Fess, 2001; Wernke \& Lembeck, 2004; Guerreiro, 2011; Wernke, 2019).

A segunda categoria de benefícios informativos abrange o ponto de equilíbrio operacional e a margem de segurança, conforme deslindado nas Tabelas 5 a 7 . Ou seja, por evidenciar o volume de faturamento (em quantidade física e em valor monetário) por produto que a fábrica deve vender para ter resultado nulo (zero) no período, com o conhecimento do ponto de equilíbrio o administrador terá uma estimativa do patamar de vendas a superar mensalmente para ter lucro. Ainda, outra informação possível refere-se à possibilidade de projetar o patamar de faturamento para alcançar determinada meta de lucro mensal (projeção de cenários).

É interessante salientar que o cálculo do ponto de equilíbrio mix abrangendo todos os produtos faturados no mês (como utilizado neste estudo) é adequado à realidade das empresas que comercializam grande quantidade de produtos e/ou cujas respectivas margens de contribuição unitárias são muito diferentes entre si (Santos, 2005; Assaf Neto \& Lima, 2009; Wernke, 2019). No caso dessa pequena indústria, os 
diversos itens à venda possuem vários níveis de margem de contribuição e volumes físicos faturados, o que favorece que seja empregada a equação aplicada neste estudo.

No caso da margem de segurança, demonstra a diferença entre a quantidade efetivamente vendida no mês abrangido e o volume necessário para atingir o ponto de equilíbrio da fábrica. Nesse sentido, uma informação como essa pode ser relevante ao mostrar o quanto as vendas podem cair sem que a empresa fique abaixo do ponto de equilíbrio, sendo especialmente útil para o caso de projeções relacionadas com a retração de vendas (Bornia, 2010).

O terceiro aspecto a salientar é que os dados coletados para aplicar a Análise CVL e as informações oriundas permitem uma fácil apuração do resultado da pequena fábrica no período, como descrito na Tabela 8. Desse modo, o gestor pode conhecer como foi formado o resultado do mês (lucro ou prejuízo) de forma simplificada, o que facilita a compreensão do demonstrativo mesmo por aqueles que não detêm conhecimentos contábeis mais específicos, conforme mencionado por Scheren et al. (2019).

\section{CONSIDERAÇÕES FINAIS}

O artigo teve o objetivo de identificar as informações gerenciais decorrentes da aplicação da Análise CVL no âmbito de uma pequena indústria de blocos de concreto, o que se considera ter sido atingido pela evidenciação de diversas informações úteis ao administrador da fábrica abrangida, como destacado nas seções precedentes.

Nessa direção, entre resultados oriundos é cabível salientar três benefícios informativos que a Análise CVL proporcionou à empresa pesquisada. $\mathrm{O}$ primeiro se refere à possibilidade de aferir a lucratividade de produtos e grupos de produtos (além de outros segmentos de mercado) pelos ângulos da margem de contribuição fabril unitária (em valor monetário e em percentual) e da margem de contribuição fabril total.

A segunda vantagem consiste em conhecer o ponto de equilíbrio operacional, cujo nível respectivo indica o patamar de vendas (em $\mathrm{R} \$$ e em unidades) a atingir para 
obter resultado mensal nulo (zero). Pode ser utilizado, também, para simular o faturamento necessário para obtenção do montante de lucro suficiente para remunerar o capital aplicado pelos proprietários de pequenas fábricas.

O terceiro benefício informativo a destacar diz respeito à facilidade de elaborar um demonstrativo do resultado de fácil entendimento até para não iniciados em contabilidade porque, ao deduzir as despesas fixas mensais da margem de contribuição fabril total obtida no período, se conhece o resultado gerencial da empresa.

Quanto à contribuição da pesquisa se reside essencialmente no aspecto prático, ou seja, de descrever como utilizar os conceitos relacionados com a Análise CVL no contexto de uma fábrica de pequeno porte. Portanto, a abordagem utilizada se associa às pesquisas acadêmicas que contribuem para facilitar o uso efetivo no cotidiano empresarial de artefatos de contabilidade gerencial comumente divulgados na literatura, conforme recomendado por Lukka (2010) e Baldvinsdottir, Mitchell e Norreklit (2010).

Entretanto, algumas limitações podem ser atribuídas à esta pesquisa. Nesse rumo, convém ressalvar que a Análise CVL possui alguns aspectos falhos. Acerca disso, além das simplificações da realidade apontadas por Leone e Leone (2008), salienta-se que a margem de contribuição não considera o conceito econômico do "valor do dinheiro no tempo", bem como desconsidera os prazos de recebimento dos clientes e de pagamento de fornecedores e tributos incidentes sobre o faturamento, o que pode distorcer o valor final da margem de contribuição de cada produto (Wernke, 2019).

Então, a título de recomendação para trabalhos futuros, sugere-se analisar a possibilidade de apurar a margem de contribuição "a valor presente", com o fito de computar os efeitos financeiros oriundos dos prazos de recebimento e pagamento dos fatores computados no cálculo da margem de contribuição dos produtos. 


\section{REFERÊNCIAS}

Andriani, R. (2018). Analisis cost-volume-profit kaitannya dengan perencanaan laba. Jurnal Kajian IImiah, 18(1).

Anthony, R. N., \& Govindarajan, V. (2002). Sistemas de controles gerenciais. São Paulo: Atlas.

Aslan, T., \& Yilmaz, E. (2018). Cost-volume-profit analysis in uncertainty conditions using Fuzzy Logic Method. İsletme Araştırmaları Dergisi, 10(2), 534-553.

Assaf Neto, A., \& Lima, F. G. (2009). Curso de administração financeira. São Paulo: Atlas.

Baldvinsdottir, G., Mitchell, F., \& Norreklit, H. (2010). Issues in the relationship between theory and practice in management accounting. Management Accounting Research, 21(2), 79-82.

Banker, R. D., Basu, S., Byzalov, D., \& Chen, J. (2020). Asymmetries in cost-volumeprofit relation: cost stickiness and conditional conservatism. SSRN Electronic Journal, march. Recuperado de: <http://dx.doi.org/10.2139/ssrn.2312179>. Acesso em: 03/fev./2021.

Bergo, G., Lucas, B., Sobreiro, V., \& Nagano, M. (2016). Multiproduct cost-volume-profit model: a resource reallocation approach for decision making. Journal of Cost Analysis and Parametrics, 9(3), 164-180.

Bornia, A. C. (2010). Análise gerencial de custos: aplicação em empresas modernas. (3a. ed.). São Paulo: Atlas.

Carmen, S., \& Sorin, B. (2010). Cost volume profit model, the break-even point and the decision making process in the hospitality industry. Annals of the University of Oradea: Economic Science, 1(2), 839-845.

Carmen-Elena, S. (2018). Sensitivity of indicators used in cost-volume-profit analysis. MATEC Web of Conferences, 184(s/n), 4003.

Corrêa, R. G. de F., Kliemann Neto, F. J., Roos, E. C., Souza, J. S. de, \& Amorin, A. L. W. (2020). Análise de Custo-Volume-Lucro multiproduto: proposta de um método de balanceamento em função da capacidade de vendas. Custos e Agronegócios Online, v.16 (Ed. Especial), 185-206. 
Chirilov, N., \& Mihaila, S. (2016). The utility of analyzing cost-volume-profit relationship through the direct-costing method for decision making process. Studia Universitatis Moldaviae: Stiinte Exacte Si Economice, 97(7), 91-96.

Chu, L., Libby, T., Mathiey, R., \& Zhang, P. (2017). Bach Music Inc.: impact of price pressure, capacity constraints, and a special order on management decision making. Accounting Perspectives, 16(4), 435-443.

Colpo, I., Medeiros, F. S. B., Amorim, A. L. W., \& Weise, A. D. (2015). Análise do CustoVolume-Lucro auxiliando na tomada de decisão: o caso de uma microempresa. Revista da Micro e Pequena Empresa, 9(3), 22-36.

Confederação Nacional da Indústria (CNI). Perfil da indústria brasileira. Recuperado de: https://industriabrasileira.portaldaindustria.com.br/grafico/total/mercadotrabalho/\#/industria-total . Acesso em: 26/fev./2021.

D’Amato, C. L, Galvão, M., Villaça, N. A. G., Jorge, R. K., \& Tavares, Z. (2012). Curso básico de finanças: entendendo finanças de maneira prática e objetiva. São Paulo: Atlas.

Deviarti, H., \& Ayu, M. (2011). Analysis cost volume profit sebagai alat bantu management dalam rangka perencanaan laba dengan penerapan teori kendala pada PT Skylite Surya Internusa. Binus Business Review, 2(1), 527-539.

Dianawati, W. (2010). Cost-volume-profit analysis untuk kondisi uncertainty. Journal Akuntansi, 2(1), 43-54.

Ekergil, V. (2017). Use of Cost-Volume-Profit analysis technique in customer profitability analysis and model suggestion for business. Işletme Araştırmaları Dergisi, 9(3), 487520.

Etges, A. P. B. da S., Calegari, R., Rhoden, M. I. dos S., \& Cortimiglia, M. N. (2016). Using cost-volume-profit to analyse the viability of implementing a new distribution center. Brazilian Journal of Operations \& Production Management, 13(1).

Fonseca, J. W. F. da. (2012). Elaboração e análise de projetos: a viabilidade econômico-financeira. São Paulo: Atlas.

Gani, E. (2013). Analisis biaya-volume-laba untuk perencanaan laba operasi. Binus Business Review, 4(2), 851-864.

Gil, A. C. (1999). Métodos e técnicas de pesquisa social. (5a. ed). São Paulo: Atlas. 
Guarini, M. R., \& Battisti, F. (2017). A model to assess the feasibility of public-private partnership for social housing. Buildings, 7(44), 1-20.

Guerreiro, R. (2011). Estruturação de sistemas de custos para a gestão da rentabilidade. São Paulo: Atlas.

Huels, B., \& Weber, J. (2020). Swimming with the sharks: An activity exploring cost, volume and profit analysis through the use of Shark Tank. Journal of Education for Business. DOI: 10.1080/08832323.2020.1719960

Ilie, R., \& Ileana-Sorina, R. (2017). Cost-volume-profit analysis: an instrument of managerial control of the economic entities in the extractive industry. Ovidius University Annals: Economic Sciences Series, 17(2), 627-632.

Johnson, B. G., \& Sargent, C. S. (2013). Impact of formulas, language and instruction on student performance on cost-volume-profit problems. Accounting Education, 23(1), 1-20.

Jonny, J. (2012). Analisis kelayakan investasi perluasan pabrik dengan metode costvolume-profit dan incremental pada PT XYZ, Jakarta. ComTech, 3(1), 524-532.

Leoncine, M., Bornia, A. C., \& Abbas, K. (2013). Sistemática para apuração de custos por procedimento médico-hospitalar. Production, 23(3), 595-608.

Leone, R. J. G., \& Leone, G. S. G. (2008). Um enfoque matemático e estatístico para a análise do custo-volume-lucro e suas hipóteses simplificadoras. Contabilidade Vista \& Revista, 19(4), 129-150.

Lima, J. D., Ferro, W. A., Bortoluzzi, S. C., Southier, L. F. P., \& Batistus, D. R. (2018). Uma proposta de ampliação na análise custo-volume-lucro por meio das análises de sensibilidade e de cenários. Exacta, 16(2), 21-41.

Lukka, K. (2010). The roles and effects of paradigms in accounting research. Management Accounting Research, 21(2), 110-115.

Martins, E. (2018). Contabilidade de Custos. (11a. ed.). São Paulo: Atlas.

Mihalciuc, C. C., \& Grosu, M. (2019). Improving the monitoring process and the external and internal communication process of na organization performance. USV Annals of Economics and Public Administration, 19(2), 141-150.

Moraes, L., C., \& Wernke, R. (2006). Análise custo/volume/lucro aplicada ao comércio de pescados. Revista Contemporânea em Contabilidade, 3(6), 81-101. 
Oyadomari, J. C. T., Cardoso, R. L., Mendonça Neto, O. R., Antunes, M. T. P., \& Aguiar, A. B. (2013). Criação de conhecimento em práticas de controle gerencial: análise dos estudos internacionais. Advances in Scientific and Applied Accounting, 6(1), 430 .

Pitoyo, R. (2018). Analysis cost volume profit dan metode activity based costing untuk Penjualan Barang Bekas. Journal Organisasi dan Manajemen, 14(1), 10-20.

Rasoto A., Gnoatto, A. A., Oliveira, A. G. de, Rosa, C. F. da, Ishikawa, G., Carvalho, H. A. de, Lima, I. A. de, Lima, J. D. de, Trentin, M. G., \& Rasoto, V. I. (2012). Gestão financeira: enfoque em inovação. Série UTFinova. Curitiba: Aymará Educação.

Richardson, R. J. (1999). Pesquisa social: métodos e técnicas. (3a. ed.). São Paulo: Atlas.

Santos, J. A., Cruz, V. L., Santos, R. R., \& Leone, R. J. G. (2018). Análise das estratégias de ganho de margem bruta em uma distribuidora de medicamentos. Exacta, 16(2), 169-185.

Santos, J. J. (2005). Formação de preços e do lucro: custos marginais para formação de preços referenciais. São Paulo: Atlas.

Santos, L. A. D., Marion, J. C., \& Kettle, W. M. (2014). Gestão estratégica de custos: um enfoque gerencial utilizando análise CVL na produção de leite da fazenda UNASP EC. Custos e Agronegócios Online, 10(3), 24-37.

Sanzonovo Neto, J. (2020). Desafios e bons resultados. Revista Super Hiper, 46(526), 3.

Serviço Brasileiro de Apoio às Micro e Pequenas Empresas - SEBRAE. (2019). Critérios de classificação do porte da empresa. Recuperado de: <http://www.sebraesc.com.br/leis/default.asp>. Acesso em: 05/ago./2021.

Scheren, G., Wernke, R., Junges, I., \& Santos, A. P. dos. (2019). Análise custo-volumelucro: aplicação em pequena indústria de alimentos com gama diversificada de produtos. Iberoamerican Journal of Industrial Engineering, 11(21), 97-121.

Schultz, C. A., Borgert, A., \& Hofer, E. (2006). A remuneração do capital de giro nas empresas agropecuárias com enfoque na análise custo/volume/lucro. Revista de Administração da Unimep, 4(2), 66-90.

Schultz, W. L. (2018). Sweet celebrations: a managerial accounting case study. Accounting Perspective, 17(4), 623,632. 
Sichigea, N., \& Ciurezu, T. (2009). The analysis of cost-profit-volume in making a decision about the volume of activity of a company. Finanţe: Provocările Viitorului, $1(9), 66-69$.

Silva, R. N. S., \& Lins, L. S. (2017). Gestão de custos: contabilidade, controle e análise. (4a. ed.). São Paulo: Atlas.

Souza, M. A., \& Diehl, C. A. (2009). Gestão de custos: uma abordagem integrada entre contabilidade, engenharia e administração. São Paulo: Atlas.

Souza, M. A., Schnorr, C., \& Ferreira, F. B. (2011). Análise das relações Custo-VolumeLucro como instrumento gerencial: um estudo multicaso em indústrias de grande porte do Rio Grande do Sul. Revista de Contabilidade e Organizações, 5(12), 109134.

Sulaiman, M., Ahmad, N. N. N., \& Alwi, N. (2004). Management accounting practices in selected asian countries: a review of the literature. Managerial Auditing Journal, 19(4), 493-508.

Trifan, A., \& Anton, C. (2011). Using cost-volume-profit analysis by management. Bulletin of the Transilvania University of Brasov. Economic Sciences Series, 4(2), 207-212.

Warren, C. S., Reeve, J. M., \& Fess, P. E. (2001). Contabilidade Gerencial. São Paulo: Pioneira, Thomson Learning.

Wernke, R. (2019). Análise de custos e preços de venda: ênfase em aplicações e casos nacionais. (2a ed.). São Paulo: Saraiva.

Wernke, R., \& Lembeck, M. (2004). Análise de rentabilidade dos segmentos de mercado de empresa distribuidora de mercadorias. Revista Contabilidade \& Finanças, 15(35), 68-83.

Wernke, R., Faccenda, L. dos S., \& Junges, I. (2018). Gestão de custos em escola de idiomas: estudo de caso com aplicação da Análise Custo/Volume/Lucro. Revista ABCustos, 13(1), 77-108.

Wibowo, S. B. (2012). Analisis estimasi cost-volume-profit (CVP) dalam hubungannya dengan perencanann laba pada Hotel Tlogo Mas Sarangan. Assets: Journal Akuntansi dan Pendidikan, 1(1), 13-23.

Winarko, S. P., \& Astuti, P. (2018). Analisis cost-volume-profit sebagai alat bantu perencanaan laba (multi produk) pada perusahaan Pia Latief Kediri. Jurnal 
Nusantara Aplikasi Manajemen Bisnis, 3(2), 9-21.

Yin, R. K. (2005). Estudo de caso: planejamento e método. Porto Alegre: Bookman.

Data de Submissão: 26/02/2021

Data de Aceite: 24/08/2021 